Unilateral electrical stimulation of the heart 7 acupuncture point to prevent emergence agitation in childrent

A prospective double blind randomized controlled trial

Nakamura N. ${ }^{1)}$, Mihara T. 2), Miwa T. ${ }^{2}$, Ka K.2)

1) National Yokohama Medical Center , Department of Anaesthesiology

2) Kanagawa Children's Medical Center, Department of Anaesthesiology

\title{
Background
}

Prevention of Emergence agitation (EA) by stimulating acupoint

Stimulating the HT7 acupuncture point bilaterally using a neuromuscular transmission monitor

$\longrightarrow$ EA was effectively prevented

risk ratio was $0.56(95 \% \text { confidence interval: } 0.36-0.86)^{1)}$

Research Question 'Is bilateral stimulation necessary?'

HT7

\section{Goal of Study}

To examine the efficacy of unilateral electrical stimulation of $\mathrm{HT7}$ to prevent EA in paediatric patients using a neuromuscular transmission monitor.

\section{Method}

- Prospective, randomized, double-blind controlled study.

- 100 children (age range, 18-96 months) undergoing inguinal hernia repair or orchiopexy under sevoflurane anaesthesia were included.

- The enrolled subjects were randomly assigned to one of the following two groups.

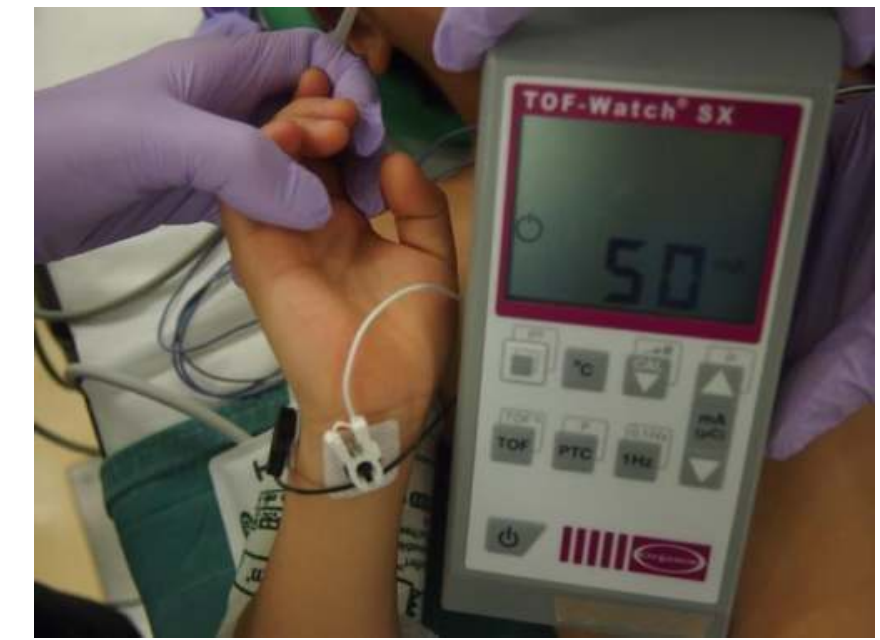

(1) HT 7 group: unilateral (right side) stimulation of the HT7 acupuncture point located on the ulnar side of the wrist using a single-twitch electrical stimulus $(1 \mathrm{~Hz}, 50 \mathrm{~mA})$ throughout the surgery.

(2) Control group: electrodes attached to the right side HT7 point; no electrical stimulus applied.

- Primary outcome: incidence of EA.

- Paediatric anaesthesia emergence delirium (PAED) score $\geq 10$ demonstrated the presence of EA.

\section{Results}

- All 100 enrolled subjects completed the study.

\begin{tabular}{lccc} 
& $\begin{array}{c}\text { HT7 } \\
(n=50)\end{array}$ & $\begin{array}{c}\text { Control } \\
(n=50)\end{array}$ & $p$ value \\
\hline Age (months) & $45(27-60)$ & $52(31-74)$ & 0.132 \\
Sex (male:female) & $37: 13$ & $37: 13$ & $>0.99$ \\
Weight $(\mathrm{kg})$ & $14.3(12.6-19.5)$ & $16.2(12.7-19.5)$ & 0.268 \\
Operation time $(\mathrm{min})$ & $24(15-67)$ & $23(14-45)$ & 0.198 \\
Anaesthesia time $(\mathrm{min})$ & $55(40-119)$ & $51(40-87)$ & 0.319 \\
Consumption of fentanyl $(\mathrm{\mu g})$ & $20(15-24)$ & $15(15-24)$ & 0.238 \\
\hline
\end{tabular}

- There was no statistical difference between the incidence of EA in the HT7 and the control groups.

- The wide range of the confidence interval precludes of any definitive conclusions.

\begin{tabular}{|c|c|c|c|c|}
\hline & $\begin{array}{c}\text { HT7 }(n=50) \\
\%(n)\end{array}$ & $\begin{array}{c}\text { Control }(n=50) \\
\%(n)\end{array}$ & $\mathrm{RR}[95 \% \mathrm{Cl}]$ & $P$ value \\
\hline A present & $28.0(14 / 50)$ & $24.0(12 / 50)$ & $1.17[0.60-2.27]$ & $>0.99$ \\
\hline
\end{tabular}

\section{Conclusion}

We did not identify a difference in the incidence of EA between the unilateral HT7 stimulation and control groups, contrary to the findings using bilateral HT7 stimulation.

1) Hijikata Toshiyuki, Mihara Takahiro, Nakamura Nobuhito, et al. Electrical stimulation of the heart 7 acupuncture site for preventing emergence agitation in children: A randomised controlled trial. Eur J Anaesthesiol 2015 